\title{
Loyalty to supervisor vs. organizational commitment: Relationships to employee performance in China
}

\author{
Zhen Xiong Chen ${ }^{1 *}$, Anne S. Tsui ${ }^{2,3}$ and Jiing-Lih Farh ${ }^{2}$ \\ 'School of Business, Hong Kong Baptist University, Hong Kong \\ ${ }^{2}$ Department of Management of Organizations, The Hong Kong University of \\ Science and Technology, Hong Kong \\ ${ }^{3}$ Peking University
}

\begin{abstract}
In this research, we investigated the relationship between loyalty to supervisor and employee's in-role and extra-role performance in comparison with that of organizational commitment in the People's Republic of China. Two studies were conducted. In the first study, a five-dimension loyalty to supervisor scale was developed and validated. In the second study, the relationships between loyalty to supervisor, organizational commitment and employee performance were examined. Results indicated that loyalty to supervisor was more strongly associated with both in-role and extra-role performance than organizational commitment. The findings are discussed in terms of their implications for future research and management practices in cross-cultural settings.
\end{abstract}

Organizational commitment, defined as the psychological attachment of workers to their organizations, has been an area of active research over the past several decades (cf. Benkhoff, 1997; Mathieu \& Zajac, 1990). Commitment to organization has been found to relate positively to a variety of desirable work outcomes including employee job satisfaction, motivation and performance, and negatively correlated to absenteeism and turnover (see Mathieu \& Zajac, 1990, for a review).

With the increased popularity of the concept of commitment, in recent years researchers have turned their attention to multiple commitments (e.g. Becker, 1992; Clugston, Howell, \& Dorfman, 2000; Morrow \& McElroy, 1993; Reichers, 1985, 1986). In addition to the organization as a focus of commitment, some other foci have been suggested, which include occupations, top management, supervisors, co-workers, work-unit and customers (e.g. Becker, 1992; Becker \& Billings, 1993; Becker Billings, Eveleth, \& Gilbert, 1996; Gregersen, 1993; Knippenberg \& Schie, 2000; Meyer, Allen, \& Smith, 1993).

Among these foci of commitment, the supervisor could be most important for employees. Acting as an agent of the organization, the supervisor often interacts with employees on a daily basis, enacting the formal and informal procedures of organized activities and, most importantly, serving as an administrator of rewards

*Requests for reprints should be addressed to Zhen Xiong Chen, School of Business, Hong Kong Baptist University, Kowloon Tong, Hong Kong (e-mail: georgezx@hkbu.edu.hk). 
to subordinates (Farh, Podsakoff, \& Organ, 1990). Despite the importance of the supervisor in employment settings, research on commitment to supervisor has begun only recently (e.g. Becker, 1992; Becker et al., 1996; Gregersen, 1993). This is in contrast with the large body of literature on organizational commitment dating back to the 1950s. Additionally, research on commitment to supervisor has been conducted primarily in Western settings. The goal of this study was to analyse the concept of commitment to supervisor and its effect in the People's Republic of China, a cultural setting where loyalty to a person is more important than loyalty to an institution (Redding, 1990).

Specifically, we aimed to address two research questions. First, what is the meaning (i.e. definition and dimensionality) of the concept of commitment to supervisor in China? Secondly, what is its relationship to employee performance, relative to organizational commitment? We used the term 'loyalty to supervisor' in lieu of commitment to supervisor in this study for two reasons: (1) Loyalty has been considered as a synonym of commitment in the literature (e.g. Hirschman, 1970; Morrow \& McElroy, 1993; Werther, 1988); and (2) in Chinese society, psychological attachment to a person is best described as personal loyalty rather than an impersonal form of commitment.

\section{Conceptual background and hypotheses}

Existing measures of loyalty to supervisor were derived from the concept of organizational commitment. The original definition of 'organizational commitment' proposed by Mowday, Porter, and Steers (1982) included three components: acceptance of organizational goals and values, extra effort on behalf of the organization, and desire to remain with the employer. They (Mowday, Steers, \& Porter, 1979; Porter, Steers, Mowday, \& Boulian, 1974) proposed a 15-item measure (i.e. Organizational Commitment Questionnaire, or OCQ) that includes all three components. However, though defined as consisting of three components, the OCQ is a unidimensional measure. Following Kelman (1958), O'Reilly and Chatman (1986) attempted to clarify the construct of organizational commitment, focusing on the bases of the employee's psychological attachment to the organization. They distinguished three bases of commitment-compliance, identification and internalization-and suggested that these three bases of commitment 'may represent separate dimensions of commitment' (p. 493).

Following O'Reilly and Chatman, Becker et al. (1996) and Gregersen (1993) focused on commitment to supervisor and defined two dimensions: identification with supervisor and internalization of supervisor's values. Identification occurs when the subordinate admires certain attributes of the supervisor, such as the supervisor's attitudes and behaviour, personality or accomplishments. They may feel proud to be associated with the supervisor (hence loyalty) who has these admired attriutes. The subordinate, however, may or may not adopt the supervisor's attributes as his or her own (cf. O'Reilly \& Chatman, 1986, p. 493). Internalization, on the other hand, occurs when the subordinate adopts the attitudes and behaviours of the supervisor because the supervisor's attitudes and behaviours are congruent with the subordinate's value systems. In other words, the values of the subordinate and his or her supervisor are similar.

Yet loyalty to supervisor may extend beyond these two dimensions, especially in a highly relationship-oriented context. It can be argued that in a relationship-oriented society such as China, loyalty to another individual may be manifested in more ways 
than mere identification with the individual or internalization of the other's values. For example, attachment may arise out of attraction based on familiarity, frequent interactions or common identity (Tsui, Egan, \& O'Reilly, 1992). In the Chinese context, loyalty may also be associated with indebtedness toward another individual for favours granted or role obligation to an authority figure because of social norms (Farh \& Cheng, 2000; Hwang, 1987; Yang, 1993). Because of the unique characteristics of the relationship-oriented Chinese society, loyalty to another individual, particularly one's superior, may take on special meaning and importance, a point fully discussed in the following section, along with a review of relevant studies conducted in the Chinese settings.

\section{Loyalty to supervisor in China and its dimensionality}

The important status of a superior is ingrained in the Chinese culture, which has its roots in Confucianism (Farh \& Cheng, 2000). In the Confucian social order, five cardinal relationships (called $w u-l u n$ ) are emphasized. These are emperor-minister, father-son, husband-wife, elder-younger brothers and friend-friend. In these dyadic relationships, individuals who occupy the inferior role (i.e. minister, wife, son and younger brother) are obliged to be obedient and loyal to their respective superiors. On the other hand, individuals occupying the superior roles (i.e. emperor, husband, father and older brother) are supposed to be benevolent and kind toward the inferior. Consequently, loyalty on the part of the inferior implies one's faithful support for the superior (from the beginning to the end), which may be illustrated by willingness to sacrifice one's self-interest for the superior, and complete dedication to the superior. As Chinese societies have evolved through the twentieth century, some of these sacred ties have weakened (e.g. the wife to the husband) or have been transformed (e.g. the minister-to-the-ruler tie was replaced by the subordinate-to-the-leader tie). However, sensitivity to social roles and their accompanied obligations remain a major characteristic of the contemporary Chinese. For example, Cheng (1995) reported that in family-owned businesses, Taiwanese bosses used loyalty as a key criterion to classify subordinates into in-group vs. out-group members. Many Chinese subordinates, to varying degrees, still feel obliged to be loyal to their superiors.

Several empirical studies, which explored the meaning of loyalty to boss from the Chinese perspective, have been conducted in Taiwan (e.g. Cheng, 1995; Lee, 1992; Zhou, 1983). Using the interview approach, Zhou (1983) found that the concept of loyalty to the boss involved identifying with the boss's goals/values and doing one's job conscientiously. By means of the critical incident method, Lee (1992) found that employees who were loyal to the boss tended to be conscientious, enthusiastic about their work, and were willing to comply with the boss's decision. Cheng (1995) described loyalty to the boss as accepting the boss's goals/values, being faithful, willing to exert extra effort, and demonstrating unreserved dedication. These studies suggest that the concept of loyalty to the boss goes beyond identification with supervisor and internalization of the supervisor's values. Rather, the meaning of this concept is expected to include the employee's behavioural tendency to exert extra effort, to be dedicated and to be faithful. Such a broadened concept is congruent with the original formulation of organizational commitment by Mowday et al. (1982).

Recently, Clugston et al. (2000) introduced a new measure of supervisor commitment by extending the three dimensions of organizational commitment by Meyer and Allen (1991) to two other foci: supervisor and work-group. The three dimensions are affective, continuance and normative commitment. Affective commitment refers to the 
employee's emotional attachment to, identification with and involvement with the organization (or supervisor). This is similar to the identification and internalization dimensions in Becker's (1992) scale of commitment to supervisor. Continuance commitment refers to the costs associated with leaving the organization (or supervisor). This is not consistent with the loyalty idea since it is calculative rather than affective or obligatory. Normative commitment refers to an employee's desire to stay with the organization (or supervisor) based on a sense of duty, loyalty or obligation. This is most consistent with the idea of loyalty in a relation-oriented society like China.

Based on the above review, we propose to broaden the construct of loyalty to supervisor to include both the relative strength of a subordinate's identification with the supervisor and his or her attachment and dedication to the particular supervisor. We propose five dimensions to capture the domain of this construct. They are:

(a) identification with the supervisor's character and accomplishments;

(b) internalization of the supervisor's values;

(c) willingness to dedicate to the supervisor or seek and promote the supervisor's welfare at the expense of personal interests;

(d) willingness to exert extra effort on behalf of the supervisor; and

(e) desire to be attached to or follow the supervisor.

For ease of presentation, we label these five dimensions as follows: identification with supervisor; internalization of supervisor's values; dedication to supervisor; extra effort for supervisor; and attachment to supervisor. Identification with supervisor and internalization of supervisor's values are the original dimensions introduced by Becker et al. (1996).

It is worth noting that even though some researchers have used the construct of trust in/loyalty to leader (e.g. Podsakoff, Mackenzie, Moorman, \& Fetter, 1990), their construct of trust in/loyalty to leader is different from that of loyalty to supervisor defined in the current study. Podsakoff $e t$ al. proposed a unidimensional, six-item measure of trust in/loyalty to leader. The items reflect the subordinate's perception of the leader's fairness and integrity, etc. It is more about the leader than the subordinate's behaviour. However, in the current study, our focus is on the subordinate's attitudes and behaviour intention toward the supervisor. Our focus also departs from cross-cultural studies of leadership or leader-member relations, especially those conducted in the Chinese setting (e.g. Chen \& Farh, 1999; Hui, Law, \& Chen, 1999). These leadership studies have a 'downward' focus while our study has an 'upward' focus, which should complement the body of knowledge that is accumulating about leadership and followership in the Chinese context. We further emphasize that the expanded definition of loyalty to supervisor may not be unique to China. We consider China a meaningful context for analysing this construct's nature and effect becaue of its strong relationship-orientation.

Relationship between loyalty to supervisor and employee performance

Mowday et al. (1982) have pointed out that among various employee outcomes, the relationship between organizational commitment and in-role performance was least encouraging. A meta-analysis of organizational commitment by Mathieu and Zajac (1990) confirmed this observation. It was found that the average correlation between organizational commitment and in-role performance was .135 for others' (primarily supervisors') ratings of in-role performance, and .054 for output measures of in-role performance. Their findings suggest that organizational commitment exerts a positive 
but weak effect on in-role performance. A recent study in Taiwan yielded similar results (Farh, Tsui, Xin, \& Cheng, 1998), showing that the correlation between organizational commitment and sales performance was .13 and the correlation was .08 when in-role performance was measured by supervisors' ratings. Studies in the US also consistently found a positive yet relatively small correlation between organizational commitment and organizational citizenship behaviour (e.g. Becker, 1992; O'Reilly \& Chatman, 1986; Shore \& Wayne, 1993).

On the premise that the supervisor is psychologically and physically more proximal to the employees than the organization (Lewin, 1943), we expected a stronger relationship between loyalty to supervisor and employee performance than between organizational commitment and employee performance. Such an expectation is consistent from Rousseau's (1989) argument that organizations cannot 'perceive', but individual managers can. A supervisor can closely interact with subordinates, perceive their behaviour time after time, and respond accordingly, whereas an organization cannot do so. Although some employee behaviour is available to the organization in the form of objective performance records such as sales, attendance or units produced, it is usually the supervisor who interprets the meaning of these data and provides a subjective judgment on the values of these numbers. Therefore, it can be speculated that an employee with a strong degree of loyalty to the supervisor may be more motivated to perform well than one with a strong degree of organizational commitment because of the employee's belief that the supervisor will observe and reward his or her good performance, whereas the organization may not.

Some evidence exists to support the above argument. Becker et al. (1996) found a stronger correlation between commitment to supervisor and in-role performance than that between organizational commitment and in-role performance. Gregersen (1993) found the relationships between commitment to supervisor and extra-role behaviour to be more enduring than the relationship between organizational commitment and extra-role performance. Both studies, however, relied on a two-dimensional measure of loyalty to supervisor. Further, given the importance of relations in China, we expected the relationship between loyalty to supervisor and performance to be even stronger in China than has been shown in the extant literature.

It is well known that Chinese are more loyal to individuals than to a system (e.g. Redding, 1990). In spite of its recent effort to build up the legal infrastructure, China remains a society characterized by rule of man (where relationships matter) more than rule of law (Chen \& Francesco, 2000; Walder, 1991). In such a society, it can be assumed that employee loyalty or disloyalty to the supervisor is likely to be more direct, salient and intense in driving employee behaviour. In comparison, employee commitment to the organization is more indirect, less salient and less intense in relating to employee behaviour. The above analysis led to the following hypothesis:

$\mathrm{H}_{1}$ Employee performance will be more strongly associated with loyalty to supervisor than with organizational commitment.

Social relationships in the Chinese society are characterized by a strong emphasis on particularistic ties (e.g. kinship, same natal origin and classmates), reciprocity (Hwang, 1987; King, 1991; Tsui \& Farh, 1997) and role obligation (Farh \& Cheng, 2000; Yang, 1993). In such a society, employee loyalty is less likely to be based on their personal identification with the supervisor and their internalization of the supervisor's values, but more likely be based on gratitude toward individualized support by the supervisor and personal role obligations for the supervisor. Gratitude and role obligations will be 
reflected in the three new dimensions of loyalty to supervisor. That is to say, for the Chinese employees, the dimensions of dedication to supervisor, extra effort for supervisor and attachment to supervisor may be more important indicators of loyalty to supervisor than identification with supervisor and internalization of supervisor's values. It is reasonable to expect that the three new dimensions would be more strongly associated with employee performance than the two original dimensions.

This expectation may be reinforced by contrasting the US and China in terms of the cultural values of individualism and collectivism (Earley, 1989, 1993) and the corresponding values of independence vs. subservience. In the US, where individualism and independence held great value, commitment to the supervisor, when it exists, is typically based on shared values and goals, and/or a respect for the supervisor as an individual. In China, where there is a greater value for collectivism and reliance on authority, commitment to the supervisor is typically based on self-sacrifice, duty and respect for the supervisor's role as an authority figure. Based on the above arguments, we further hypothesized:

$\mathrm{H}_{2}$ Employee performance will be more strongly associated with the dimension of, dedication, exertion of extra effort and desire to attach to the supervisor than with the dimensions of identification with and internalization of supervisor's values.

We conducted two studies to investigate loyalty to supervisor in China. In Study 1 involving two samples, we developed and validated an expanded loyalty to supervisor scale. In Study 2 involving a third sample, we obtained survey data to test $\mathbf{H}_{1}$ and $\mathrm{H}_{2}$. For ease of presentation, we use LS and OC to represent loyalty to supervisor and organizational commitment respectively in the subsequent sections of this article.

\section{STUDY I: CONSTRUCT DEVELOPMENT AND VALIDATION}

In Study 1, we used an interview and a survey sample to develop and validate the expanded LS scale. An interview sample was used to generate item pool for the LS scale. The items were then screened and selected, resulting in a 25 -item scale. This scale, along with items from Becker et al.'s (1996) scale, was tested using the survey sample. Throughout the study, materials were either developed indigenously in Chinese or translated from English using the standard translation and back-translation procedure (Brislin, 1980).

\section{Method}

\section{Item generation}

\section{Sample}

Sample 1 consisted of 20 Chinese employees from six companies in China. This sample had an average age of 29.70 , educational level of 13.35 years and organizational tenure of 2.75 years. Half of the respondents were non-supervisory employees, and $85 \%$ of them were male.

\section{Procedure}

Each respondent was asked, either by telephone or in a face-to-face interview, to list three-four statements that best describe loyalty to supervisor. Because LS is a popular concept in Chinese, all respondents understood it, and there was no need for the 
researchers to provide them with a definition or examples. We obtained a total of 36 statements describing subordinate attitude of LS. These statements (items) were then transcribed on to cards for screening.

\section{Item screening}

Three bilingual researchers screened the 36 items for redundancy and clarity. After numerous discussions, the group agreed to discard 11 items that were redundant or too vague. The remaining 25 items were retained for further testing. Only two of the 25 items retained were similar to Becker et al.'s (1996) items of commitment to supervisor. To ensure content validity and facilitate future comparative research, we added eight items from Becker et al.'s (1996) scale for further testing. This resulted in a 33-item scale. All items were measured using a 7 -point Likert scale $(1=$ strongly disagree, 7-strongly agree).

\section{Validation of the Chinese loyalty to supervisor scale}

\section{Sample}

We validated the 33-item scale by obtaining a second sample of 253 employees. We obtained a response rate of $84 \%$ (300 questionnaires were distributed) from five organizations. This sample had an average age of 26.01, educational level of 11.11 years and organizational tenure of 2.72 years. Of the respondents, $65 \%$ were nonsupervisory employees, and 56\% were male.

\section{Factor analysis}

Exploratory factor analyses were conducted to examine the underlying structure of the 33 -item scale. The initial factor analysis resulted in five factors, accounting for $52 \%$ of the total variance. To arrive at a meaningful and interpretable factor structure, we applied the following three criteria to screen items. First, the item must have a minimum loading of .40 or greater on a factor. Secondly, the item must have low crossloading on other factors. Thirdly, the content of the items retained must be consistent with those of the other items loaded on the same factor. An item was retained if it met one or more of the three criteria. Using this procedure, we retained 17 items for the final scale, accounting for $66.97 \%$ of the total variance. Table 1 presents the results of factor analysis of the 17 items.

Table 1 shows that the LS scale consisted of five distinct factors. The five factors or dimensions are labelled and interpreted as follows:

(1) Dedication to supervisor. This dimension refers to a subordinate's willingness to dedicate him- or herself to the supervisor and to protect the supervisor's welfare even at the expense of personal interests. It consists of four items with a Cronbach alpha of .72 .

(2) Extra effort for supervisor. This dimension indicates a subordinate's willingness to exert considerable effort on behalf of the supervisor. It cosists of three items with a Cronbach alpha of 79 .

(3) Attacbment to supervisor. This dimension refers to a subordinate's desire to be attached to and follow the supervisor. It consists of four items with a Cronbach alpha of .76 .

(4) Identificaiton with supervisor. This dimension refers to a subordinate's respect for the accomplishments of the supervisor, and a feeling of pride in being a 
Zhen Xiong Chen et al.

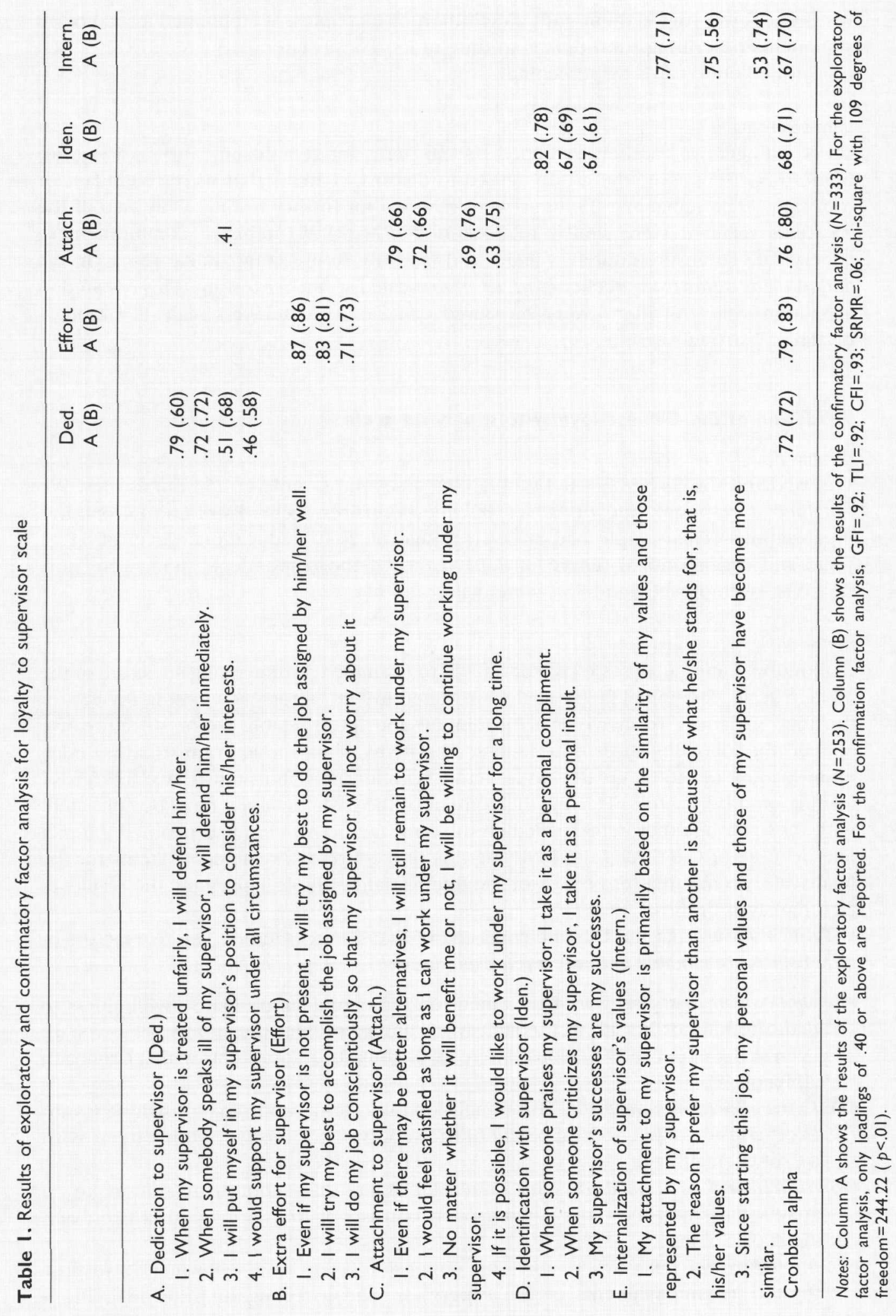


subordinate to that supervisor. It consists of three items with a Cronbach alpha of .68. All items in this scale are from Becker et al.'s (1996) scale.

(5) Internalization of supervisor's values. This dimension refers to value congruence between the subordinate and the supervisor. It consists of three items with a Cronbach alpha of .67. All items in this scale are from Becker et al.'s (1996) scale.

Among the above five dimensions, dedication to supervisor, extra effort for supervisor and attachment to supervisor are labelled as extended dimensions because they were newly developed from the current study, while identification with supervisor and internalization of supervisor's values are labelled as original dimensions because they were taken from Becker et al.'s (1996) scale.

\section{Discriminant validity of the loyalty to supervisor scale}

To assess the discriminant validity of the LS scale, we included two conceptually similar scales, Organizational Commitment Questionnaire (OCQ; Mowday et al., 1982) and Trust in Supervisor Scale (Roberts \& O'Reilly, 1974) in our pilot survey sample. We factor analysed our LS scale including items from these two scales. The exploratory factor analysis resulted in seven scales: five for LS, one for OC and one for trust in supervisor. Only one LS item had cross-loading. These results suggested that the LS scale is distinct from the $\mathrm{OC}$ and trust in supervisor measures.

\section{STUDY 2: HYPOTHESES TESTING}

\section{Method}

\section{Sample and procedures}

The sample of Study 2 consisted of employees from 36 companies in Guangzhou and Shanghai, two of the most developed cities in China. The companies represented two broad industry groups, manufacturing and service. The companies in the manufacturing group included manufacturers of motorcycles, medicines, clothing, textile, etc. The companies in the service group included supermarkets, hotels, marketing research, transportation, etc. 'The employees and managers represented different levels in the organizations.

In the survey, two versions of questionnaires were used: a supervisor and a subordinate questionnaire. Both questionnaires were first distributed to the supervisors. Each supervisor was asked to select three of his or her direct subordinates and to rate the performance of each of them. Then the supervisors distributed the subordinate surveys to the three subordinates whom they had rated. All respondents sealed the completed questionnaires in envelopes and returned them to the human resource managers of the companies or to the researchers directly. In total, 170 supervisor questionnaires and 510 subordinate questionnaires were distributed; 142 supervisor questionnaires and 377 subordinate questionnaires were returned. The response rates were $83.5 \%$ and $74 \%$ respectively. After deleting uncompleted and unmatched questionnaires, a total of 333 sets of supervisor-subordinate questionnaires remained and constituted the sample for this study.

The sample of subordinates had an average age of $27.00(\mathrm{SD}=6.53), 12.18$ years of education $(\mathrm{SD}=2.84)$ and 2.70 years of organizational tenure $(\mathrm{SD}=3.54)$. Of the respondents, $80 \%$ were non-supervisory employees and $42.5 \%$ were male. The sample of supervisors had an average age of 29.85 years $(\mathrm{SD}=6.93), 13.38$ years of education 
$(\mathrm{SD}=2.77)$ and 3.83 years of organizational tenure $(\mathrm{SD}=4.13)$. Of these, $59 \%$ were first-line supervisors, $29 \%$ middle managers, $12 \%$ top managers and $52 \%$ of them were male.

\section{Measures}

Unless noted otherwise, all multi-item scales were measured on a 7-point Likert scale ( $1=$ strongly disagree, $7=$ strongly agree).

\section{Loyalty to supervisor}

The 17-item loyalty to supervisor scale developed in Study 1 was used. Using LISREL 8 (Jöreskog \& Sörbom, 1993), we conducted a confirmatory factor analysis on the 17 items, the results of which are presented in Table 1 . All of the fit indices fell within an acceptable range $\left(\chi^{2}(109)=244.22, \mathrm{GFI}=.92, \mathrm{TLI}=.92, \mathrm{CFI}=.93, \mathrm{SRMR}=.06\right)$, suggest ing that the data fit the model well. The alpha coefficients of the five dimensions (i.e. dedication to supervisor, extra effort for supervisor, attachment to supervisor, identification with supervisor and internalization of supervisor's values) were $.72, .83, .80, .71$ and 70 , respectively.

\section{Organizational commitment}

Two scales were used to measure the organizational commitment dimensions of value commitment and commitment to stay (Angle \& Perry, 1981). A 10-item OCQ (Mowday et al., 1982) was used to measure value commitment. A four-item scale developed by Farh et al. (1998) was used to measure commitment to stay. We performed a confirmatory factor analysis using LISREL 8 (Jöreskog \& Sörbom, 1993) to test if the twodimensional model fit our data. The fit indices fell within an acceptable range $\left(\chi^{2}(64)=227.47, \mathrm{GFI}=.89, \mathrm{TLI}=.89, \mathrm{CFI}=.91\right.$, SRMR $\left.=.06\right)$, suggesting that the model fit the data reasonably well. The alpha coefficients of the scales of value commitment and commitment to stay were .87 and .81 , respectively.

\section{Performance}

Supervisors rated the performance of their subordinates. Two performance measures were used. The first was 'in-role performance', measured by a scale taken from Farh and Cheng (1997). The scale consists of four items including:

(a) makes significant contribution to the overall performance of our work unit;

(b) always completes job assignments on time;

(c) is one of the best employees in our work unit; and

(d) performance always meets the expectations of the supervisor.

The Cronbach alpha of this scale was $\mathbf{8 0}$. The second scale measured the employee's 'organizational citizenship behavior (OCB)'. We took 13 items from the indigenous Chinese OCB scale developed in Taiwan by Farh, Earley, and Lin (1997) to measure three etic dimensions of OCB: boosterism (labelled as identification in Farh et al., 1997), altruism and conscientiousness. We performed a confirmatory factor analysis using LISREL 8 (Jöreskog \& Sörbom, 1993) to test if the three-dimensional model fit our data. The fit indices fell within an acceptable range $\left(\chi^{2}(62)=172.15, \mathrm{GFI}=.93\right.$, TLI $=.89$, $\mathrm{CFI}=.92, \mathrm{SRMR}=.05$ ), suggesting that the model fit the data reasonably well. The alpha coefficients of the three dimensions of $O C B$ were $.72, .81$ and .68 , respectively.

\section{Control variables}

Five subordinate demographic variables-age, education, company tenure, gender and position-were included as control variables in this study. They were included 
because previous research has shown these demographics to be associated with in-role and extra-role performance of employees (e.g. Mathieu \& Zajac, 1990; Organ \& Ryan, 1995; Tang \& Feng, 1996). Age, education and tenure were measured by number of years. Gender was coded 1 for male and 0 for female. Position was coded 1 for non-supervisor, 2 for first-line supervisor, 3 for middle manager and 4 for top manager.

\section{Results}

The means, SDs, reliabilities and intercorrelations of all the variables in Study 2 are reported in Table 2 . There is no definitive criterion for the level of correlation that constitutes a serius multicollinearity problem among the independent variables. The general rule of thumb is that it should not exceed .75 (Tsui, Ashford, Clair, \& Xin, 1995 , p. 1531). In our sample, the highest correlation was between dedication and internalization at $r=57$. This level of correlation does not suggest a problem of multicollinearity. In addition, we performed a regression diagnostic test. The results revealed the variance inflation factor (VIF) values to range from 1.46 to 2.42. Our VIF values were much lower than the recommended cut-off threshold of 10 (Hair, Anderson, Tatham, \& Black, 1992), suggesting the absence of multicollinearity in the data. Because the independent variables (loyalty to supervisor and organizational commitment) and the dependent variables (in-role performance and OCB) were obtained from different sources, there is no common method variance problem in this study.

To test our hypotheses, we regressed in-role performance and $\mathrm{OCB}$ on the five dimensions of LS and the two dimensions of $\mathrm{OC}$. We estimated the unique variance by the two dimensions of $\mathrm{OC}$, the two original LS dimensions, and the three extended LS dimensions separately. Table 3 presents the results of this analysis. As can be seen from the table, after controlling for the five dimensions of LS and demographic variables, the two dimensions of $\mathrm{OC}$ had no effect on any of the OCB dimensions or in-role performance. In contrast, LS had a significant effect on two of the OCB dimensions (i.e. boosterism and conscientiousness) and in-role performance, after controlling for $\mathrm{OC}$ and demographic variables. These results provided support for $\mathrm{H}_{1}$. Further, none of the beta coefficients for identification with supervisor or internalization of supervisor's values was significant for any of the OCB dimensions and in-role performance. In contrast, dedication to supervisor was significant for two OCB dimensions (i.e. boosterism and conscientiousness), and extra effort for supervisor was significant for in-role performance. The two original dimensions as a block did not account for any significant variance in the dependent variables, whereas the three extended dimensions as a block accounted for a significant amount of variance in three of the four performance measures. They accounted for $3 \%$ of unique variance for boosterism, $2 \%$ for altruism, 5\% for conscientiousness and 5\% for in-role performance. These results provided support for $\mathrm{H}_{2}$.

\section{Discussion}

A number of theoretical implications may be derived from the results of the current study. First, the results suggest that there are more than two dimensions for the loyalty to supervisor construct (Becker et al., 1996). The two original dimensions developed in Western settings (i.e. identification with supervisor and internalization of supervisor's values) did not predict performance outcomes in the present Chinese sample. It is interesting that two of the three newly extended dimensions (i.e. dedication to 


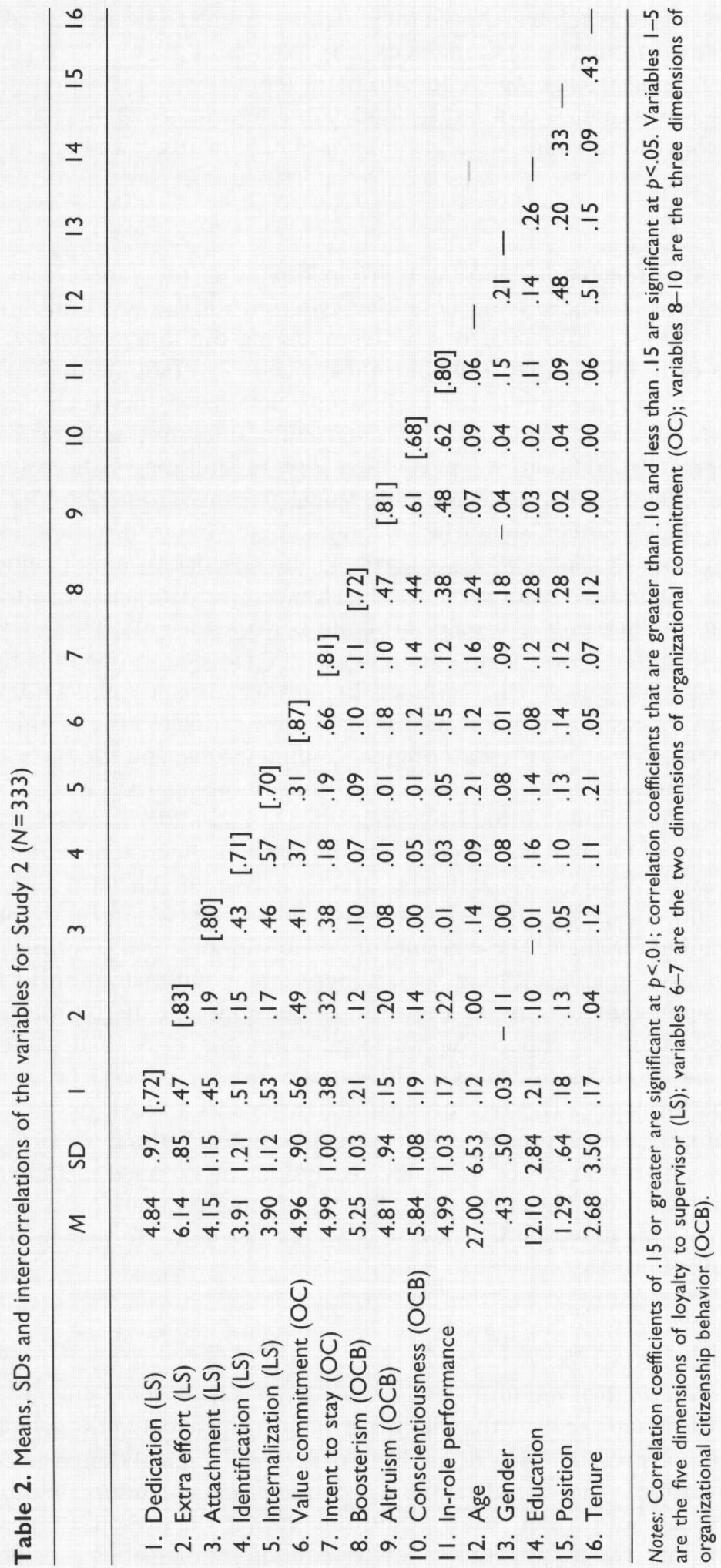


Table 3. Regression analysis of effects of loyality to supervisor and organizational commitment on employee performance controlling for individual demographics

\begin{tabular}{|c|c|c|c|c|}
\hline \multirow[b]{2}{*}{ Variable } & \multicolumn{3}{|c|}{ OCB } & \multirow{2}{*}{$\begin{array}{c}\text { In-role } \\
\text { performance } \\
\beta\end{array}$} \\
\hline & $\begin{array}{c}\text { Boosterism } \\
\beta\end{array}$ & $\begin{array}{c}\text { Altruism } \\
\beta\end{array}$ & $\begin{array}{c}\text { Conscientiousness } \\
\beta\end{array}$ & \\
\hline \multicolumn{5}{|l|}{ Individual demographics } \\
\hline Age & $.16 *$ & .11 & .13 & .01 \\
\hline Gender & .10 & -.03 & .05 & $.16^{* *}$ \\
\hline Education & $.17^{* *}$ & .02 & -.07 & -.03 \\
\hline Position & $.14 *$ & -.05 & -.02 & .00 \\
\hline Tenure & -.07 & -.04 & -.07 & -.02 \\
\hline Unique $R^{2}$ & $.12^{* *}$ & .01 & .02 & .03 \\
\hline \multicolumn{5}{|l|}{ OC } \\
\hline Value commitment & -.06 & .14 & -.09 & .04 \\
\hline Commitment to stay & -.00 & -.06 & .13 & .02 \\
\hline Unique $R^{2}$ & .00 & .01 & .01 & .00 \\
\hline \multicolumn{5}{|l|}{$\mathrm{LS}_{0}$} \\
\hline Identification & -.04 & -.08 & .04 & -.04 \\
\hline Internalization & -.07 & -.07 & -.12 & -.03 \\
\hline Unique $R^{2}$ & .01 & .01 & .01 & .00 \\
\hline \multicolumn{5}{|l|}{$\mathrm{LS}_{\mathrm{e}}$} \\
\hline Dedication & $.18^{* * *}$ & .10 & $.26 * *$ & .16 \\
\hline Extra effort & .05 & .12 & .07 & $.18^{* *}$ \\
\hline Attachment & .06 & .04 & -.12 & -.06 \\
\hline Unique $R^{2}$ & $.03 *$ & .02 & $.05^{* *}$ & $.04 * *$ \\
\hline Overall $R^{2}$ & .17 & .07 & .08 & .09 \\
\hline Overall model $F$ & $5.09 * *$ & $1.82 *$ & $2.23^{* *}$ & $2.43^{* *}$ \\
\hline d.f. & 12,302 & 12,302 & 12,302 & 12,302 \\
\hline
\end{tabular}

$p<.05 ; * * p<.01$ (two-tailed).

Notes: $\mathrm{OC}=$ organizational commitment with two dimensions, i.e. value commitment and commitment to stay; $\mathrm{LS}_{\mathrm{o}}=$ loyalty to supervisor with two original dimensions developed by Becker et al. (1996), i.e. identification with supervisor and internalization of supervisor's values; LS $_{e}=$ loyalty to supervisor with three extended dimensions developed by the authors through interviews of the Chinese employees, i.e. dedication to supervisor, extra effort for supervisor and attachment to supervisor.

supervisor and extra effort for supervisor) were associated with supervisory ratings of employee performance on both organizational citizenship behaviour and in-role performance. It is worth noting that the two original LS dimensions are value-oriented, while the extended dimensions discovered in this study are more behaviour-intentionoriented. Our suggestion that the LS construct consists of both value-oriented and behaviour-intention-oriented dimensions is consistent with the original formulation of organizational commitment proposed by Mowday et al. (1982). Mowday et al. proposed that $\mathrm{OC}$ included three components: acceptance of organizational goals and values (value-oriented); extra effort on behalf of the organization (behaviour-intentionoriented); and desire to remain with the employer (behaviour-intention-oriented). The behaviour-intention-oriented (intend to do something in the future) dimensions of LS should be regarded as attitude rather than behaviour (something has been done) per se. Obviously, the behaviour-intention-oriented components of LS such as willingness 
to exert extra effort (behaviour intention only) should be different from the OCB components such as conscientiousness (behaviours that have been really performed by a subordinate and observed by a supervisor). Thus, it should be reasonable to include behaviour-intention-oriented components in measuring LS.

The inclusion of behaviour-intention-oriented dimensions (dedication, extra effort and attachment) broadens the construct domain of LS, making it more useful for research across cultural settings. In a collectivistic society such as China, belief in values does not figure prominently in determining individual behaviour as in an individualistic society such as the US. By implication, value congruence may not be a meaningful basis of interpersonal loyalty in a collectivistic society. Other factors such as reciprocity and role obligation may be more important. By including behaviourintention-oriented dimensions in the construct, we overcome the limitation of over-reliance on value congruence and make the construct more relevant across cultures.

Another implication of our findings is that loyalty to supervisor seems to be more important than organizational commitment in accounting for employee's in-role and extra-role performance. This finding is consistent with the idea that to the Chinese, loyalty to a person (i.e. supervisor) is more important than commitment to a system (i.e. the organization). These findings are also quite consistent with that of earlier research using Western samples (Becker et al., 1996; Gregersen, 1993). It could be that loyalty to supervisor and its stronger effects on employee outcomes (relative to commitment to organization) is an etic phenomenon (i.e. it has generality across cultural settings). This means that the cultural differences on the meaning and effect of loyalty to a supervisor, relative to commitment to an organization, could be more in degree than in kind. Therefore, $\mathrm{H}_{1}$ might capture a pan cultural phenomenon.

This study also found that employee performance was more strongly associated with the dimensions of dedication to and exert extra effort for supervisor than with the dimensions of identification with and internalization of supervisor's values $\left(\mathrm{H}_{2}\right)$. While this finding is consistent with the argument that Chinese society places strong emphasis on reciprocity and role obligation, we also do not intend to argue that it is unique to China. We are simply arguing that the extended dimensions would be more strongly associated with employee performance in settings where there is a high respect for and obedience to those in positions of authority. In such settings or for individuals with these cultural values, supervisors would expect and employees would offer dedication and extra effort. To the extent that all supervisors value dedication and extra effort, it is reasonable to expect that $\mathrm{H}_{2}$ may not be unique to China.

Clearly, further testing of these hypotheses in cultures that differ from China in terms of personal vs. institutional loyalty would be desirable. Since the LS scale was developed in a Chinese context, future research may examine the construct validity of this scale in other cultural settings. Would the three extended dimensions be meaningful in other cultures, including the US? In addition to its effect (e.g. on performance), would there be cultural differences in the extent (i.e. level) to which employees are loyal to their supervisors? Studies using the extended dimensions in other cultural settings might provide further understanding of the LS construct.

Research should also examine the antecedents of loyalty to supervisor. What are the likely determinants of such loyalty? For example, the potential antecedents of LS might include trust in supervisor, guanxi with supervisor, supervisor consideration, supervisor communication, supervisor competence, supervisor virtue, supervisor integrity and relational demography. Cross-cultural studies of the determinants of such loyalty 
would provide useful insight for cross-cultural management in general and leadership specifically.

The relationships between loyalty to supervisor and a variety of consequences, such as attendance, lateness, turnover and job satisfaction, also need to be studied. Supervisor is one of the foci of commitment. The relationships among different types of foci of commitment need to be assessed in future studies, too. For example, what are the relationships between $L S$ and commitment to top management, commitment to co-worker and commitment to work group, in China and elsewhere?

Several limitations of the present study need to be noted. First, the OCQ (Mowday et al., 1982) developed in the US might be limiting when used with Chinese employees. Because some of the items in this scale may not be suitable in a Chinese setting, it might not be able to capture the full or true meaning of organizational commitment in China. Thus, measurement slippage might contribute to the lack of significant results. Even though researchers have used the OCQ to measure organizational commitment among Taiwanese employees (e.g. Cheng, 1993; Farh et al., 1997, 1998; Yang \& Cheng, 1987), future research is needed to validate this scale, using procedures similar to those used in this and other studies (e.g. Farh et al., 1997).

The second weakness in this study is that the performance measures were based on subjective perceptions of the supervisors. Ideally, we should use objective performance measures. Further, we used a cross-sectional design, which constrains any inference of causality between IS and employee performance. Future research that uses a longitudinal design will be particularly useful in establishing the causal order of the relationships reported in this study.

In addition the loyalty scales accounted for only a relatively small amount of variance in the performance measures. However, the magnitude of the effects observed in this study are consistent with those found in previous studies when performance is the outcome measure. A meta-analytic study (e.g. Mathieu \& Zajac, 1990) has found the relationship between commitment and performance (zero-order correlation) to be around .05 and .13 , even less than the amount of variance accounted for in the current study. The small amount of variance accounted for might be owing to measurement problems in both the independent and dependent variables. For example, the extra effort and the conscientiousness scales have very high mean scores (6.14 and 5.84, respectively on a 7-point scale). Ceiling effect on these measures could have depressed the possible covariation with the performance variable. Further, employee performance could be influenced by a number of factors. One of these could be the employee's loyalty to the supervisor or commitment to the organization. Therefore, for both substantive and measurement reasons, we are not totally surprised, though slightly disappointed, by the small amount of variance found in this study. However, the study does not have a common method variance problem. Therefore, the systematic relationship between supervisory loyalty and performance ratings is meaningful and worthy of further understanding and study, especially in context with strong relationship or hierarchical orientation.

To conclude, the current study focused on loyalty to supervisor, a construct that is, we propose, especially meaningful in the cultural fabric of China. In a relation-oriented society, the supervisor may be a more important factor in influencing employee behaviour and attitudes at work than the organization as an impersonal entity. Even though the pattern of our results may be stronger in a Chinese setting than in the West, our findings may not be unique to China. We hope our study may constribute to universal understanding of loyalty to supervisor in two ways: 
(1) The five-dimension LS scale proposed in the current study may serve as a more comprehensive and meaningful measure for LS construct in general.

(2) Supervisor (a person or an agent of a system) may be more important than organization (a system) in influencing employees' performance.

In any organization, regardless of the extent of institutionalism, a supervisor may still be psychologically and physically more proximal to employees than the impersonal system (i.e. organization). In turn, employees' attitude towards a supervisor (e.g. loyalty to supervisor) will have stronger impact on employees' performance than employees' attitude towards the organization (e.g. OC). Further systematic research in different cultural contexts, indigenous and comparative, is needed to test the generality or limits of existing theories and models that were largely developed in the Anglo-Saxon Western culture and tradition.

\section{Acknowledgements}

This work was supported by grants from the Research Grants Council of the Hong Kong Special Administrative Region, China (Projects KHBU 2025/98H; HKUST 6245/97H), a grant from the Research Committee, Hong Kong Baptist University (Project FRG/97-98/II-22), and an Areas of Excellent grant from the Hong Kong University of Science and Technology (Project HIA98/ 99.BM.01).

\section{References}

Angle, H. L., \& Perry, J. L. (1981). An empirical assessment of organizational commitment and organizational effectiveness. Administrative Science Quarterly, 26, 1-14.

Becker, T. E. (1992). Foci and bases of commitment: Are they distinctions worth making? Academy of Management Journal, 35, 232-244.

Becker, T. E., \& Billings, R. S. (1993). Profiles of commitment: An empirical test. Journal of Organizational Bebavior, 14, 177-190.

Becker, T. E., Billings, D. M., Eveleth, D. M., \& Gilbert, N. L. (1996), Foci and bases of employee commitment: Implications for job performance. Academy of Management Joumal, 39, $464-482$.

Benkhoff, B. (1997). Ignoring commitment is costly: New approaches establish the missing link between commitment and performance. Human Relations, 50, 701-726.

Brislin, R. W. (1980). Translation and content analysis of oral and written material. In H. C. Triandis \& J. W. Berry (Eds.), Handbook of cross-cultural psychology: Vol. 2. Methodology (pp. 349-444). Boston: Allyn and Bacon.

Chen, X. P., \& Farh, J. L. (1999). The effectiveness of transactional and transformational leader behaviors in Chinese organizations: Evidence from Taiwan. Paper presented at the Academy of Management Annual Meeting, Chicago.

Chen, Z. X., \& Francesco, A. M. (2000). Employee demography, organizational commitment and turnover intentions in China: Do cultural differences matter? Human Relations, 53, 869887.

Cheng, B. S. (1993). The effect of organizational value on organizational commitment, organizational citizenship behavior, and job performance: A comparison of different weighting model and discrepancy model. Chinese Journal of Psycbology, 35, 43-58 (in Chinese).

Cheng, B. S. (1995). Cbinese CEO's employee categorization and managerial bebavior. Paper presented at the Symposium on Indigenous Behavior in Effective Management and Organizations, sponsored by the International Association of Applied Psychology, Guangzhou, China.

Clugston, M., Howell, J. P., \& Dorfman, P. W. (2000). Does cultural socialization predict multiple bases and foci of commitment. Journal of Management, 26, 5-30. 
Earley, P. C. (1989). Social loafing and collectivism: A comparison of the United States and the People's Republic of China. Administrative Science Quarterly, 34, 565-581.

Earley, P. C. (1993). East meets West meets Mideast: Further explorations of collectivistic and individualistic work groups. Academy of Management Journal, 36, 319-348.

Farh, J. L., \& Cheng, B. S. (1997). Modesty bias in self-ratings in Taiwan: Impact of item wording, modesty value, and self-esteem. Chinese Journal of Psychology, 39, 103-118.

Farh, J. L., \& Cheng, B. S. (2000). A cultural analysis of paternalistic leadership in Chinese organizations. In J. T. Li, A. S. Tsui \& E. Weldon (Eds.), Management and organizations in the Cbinese context (pp. 84-127). London: MacMillan.

Farh, J. L., Earley, P. C., \& Lin, S. C. (1997). Impetus for action: A cultural analysis of justice and organizational citizenship behavior in Chinese society. Administrative Science Quarterly, $42,421-444$.

Farh, J. L., Podsakoff, P. M., \& Organ, D. W. (1990). Accounting for organizational citizenship behavior: Leader fairness and task scope versus satisfaction. Journal of Management, 16, $705-721$

Farh, J. L., Tsui, A. S., Xin, K. R., \& Cheng, B. S. (1998). The influence of relational-demography and Guanxi: The Chinese case. Organization Science, 9, 471-488.

Gregersen, H. B. (1993). Multiple commitments at work and extrarole behavior during three stages of organizational tenure. Journal of Business Research, 26, 31-47.

Hair, J. E., Anderson, R. E., Tatham, R. L., \& Black, W. C. (1992). Multivariate data analysis with readings. New York: MacMillan.

Hirschman, A. O. (1970). Exit, voice, and loyalty: Responses to decline in firms, organizations, and states. Harvard University Press.

Hui, C., Law, K., \& Chen, Z. X. (1999). A structural equation model of the effects of negative affectivity, leader-member exchange, and perceived job mobility on in-role and extra-role performance: A Chinese case. Organizational Bebavior and Human Decision Processes, $77,3-21$.

Hwang, K. K. (1987). Face and favor: The Chinese power game. American Journal of Sociology, 92, 944-974.

Jöreskog, K. G., \& Sörbom, D. (1993). LISREL 8: Structural equation modeling with the SIMPLIS command language. Chicago: Scientific Software International.

Kelman, H. C. (1958). Compliance, identification, and internalization: Three processes of attitude change. Journal of Conflict Resolution, 2, 51-60.

King, A. Y. (1991). Kuan-hsi and network building: A sociological interpretation. Daldalus, 120, 63-84.

Knippenberg, D. V., \& Schie, E. C. M. V. (2000). Foci and correlates of organizational identification. Journal of Occupational and Organizational Psychology, 73, 137147.

Lee, M. H. (1992). An explanation of the significance, influencing factors, and the results of behaviors of loyalty to organization: A case of middle and small enterprises in Taiwanese. Master Dissertation: Institute of Applied Psychology of Fu Ren University, Taiwan (in Chinese).

Lewin, K. (1943). Defining the 'field at a given time'. Psychological Review, 90, 125-152.

Mathieu, J. E., \& Zajac, D. (1990). A review and meta-analysis of the antecedents, correlates, and consequences of organizational commitment. Psycbological Bulletin, 108, 171-194.

Meyer, J. P., \& Allen, N. J. (1991). A three-component conceptualization of organizational commitment. Human Relations, 1, 61-89.

Meyer, J. P., Allen, N. J., \& Smith, C. A. (1993). Commitment to organizations and occupations: Extension and test of a three-component conception. Journal of Applied Psychology, 78 , 538-551

Morrow, P. C., \& McElroy, J. C. (1993). Introduction: Understanding and managing loyalty in a multi-commitment world. Journal of Business Research, 26, 1-2. 
Mowday, R. T., Porter, L. W., \& Steers, R. M. (1982). Employee-organization linkages: The psychology of commitment, absenteeism, and turnover. San Diego, CA: Academic Press.

Mowday, R. T., Steers, R. M., \& Porter, L. W. (1979). The measurement of organizational commitment. Journal of Vocational Bebavior, 14, 224-247.

O'Reilly, C. A. III, \& Chatman, J. (1986). Organizational commitment and psychological attachment: The effects of compliance, identification, and internalization on prosocial behavior. Journal of Applied Psycbology, 71, 492-499.

Organ, D. W., \& Ryan, K. (1995). A meta-analysis review of attitudinal and dispositional predictors of organizational citizenship behavior. Personnel Psychology, 48, 775-802.

Podsakoff, P. M., Mackenzie, S. B., Moorman, R. H., \& Fetter, R. (1990). Transformational leader behaviors and their effects on followers' trust in leader, satisfaction, and organizational citizenship behaviors. Leadership Quarterly, 1, 107-142.

Porter, L. W., Steers, R. M., Mowday, R. T., \& Boulian, P. V. (1974). Organizational commitment, job satisfaction, and turnover among psychiatric technicians. Journal of Applied Psychology, 59, 603-609.

Redding, S. G. (1990). The spirit of Chinese capitalism. Berlin: Walter de Gruyter.

Reichers, A. E. (1985). A review and reconceptualization of organizational commitment. Academy of Management Review, 10, 465-476.

Reichers, A. E. (1986). Conflict and organizational commitments. Journal of Applied Psycbology, 71, 508-514.

Roberts, K. H., \& O'Reilly, C. A. (1974). Measuring organizational communication. Journal of Applied Psycbology, 59, 321-326.

Rousseau, D. M. (1989). Psychological and implied contracts in organizations. Employee Responsibilities and Rights Journal, 2, 121-139.

Shore, L. M., \& Wayne, S. J. (1993). Commitment and employee behavior: Comparison of affective commitment and continuance commitment with perceived organizational support. Journal of Applied Psycbology, 78, 774-780.

Tang, W. F., \& Feng, T. (1996). Labor relations in Chinese enterprises. Hong Kong Journal of Social Sciences, 8, 85-103 (in Chinese).

Tsui, A. S., Ashford, S. J., Clair, L., \& Xin, K. R. (1995). Dealing with discrepant expectations: Response strategies and managerial effectiveness. Academy of Management Journal, 38 , $1515-1543$.

Tsui, A. S., Egan, T. D., \& O'Reilly, C. A. (1992). Being different: Relational demography and organizational attachment. Administrative Science Quarterly, 37, 549-579.

Tsui, A. S., \& Farh, J. L. (1997). Where guanxi matters: Relational demography and guanxi in the Chinese context. Work and Occupations, 24, 56-79.

Walder, A. G. (1991). Workers, managers, and the state: The reform era and the political crisis of 1989. China Quarterly, 127, 467-492.

Werther, W. B. Jr (1988). Loyalty at work. Business Horizons. March-April, 28-35.

Yang, K. S. (1993). Chinese social orientation: An integrative analysis. In L. Y. Cheng, F. M. C. Cheung \& C. N. Chen (Eds), Psychotberapy for the Chinese: Selected papers from the first international conference (pp. 19-56). Hong Kong: Chinese University of Hong Kong.

Yang, K. S., \& Cheng, K. S. (1987). Confucian values, individual modernity, and organizational behavior: An empirical test of post-Confucian hypotheses. Bulletin of the Institute of Etbnology Academian Sinica, 64, 1-49 (in Chinese).

Zhou, Y. H. (1983). The relationship between Chinese value system and managerial bebaviors in large enterprises in Taiwan. Unpublished PhD dissertation, Institute of Business and Management, National Chengchi University, Taiwan (in Chinese).

Received 19 October 2000; revised version received 26 November 2001 